\title{
Participatory impact assessment of ticks on cattle milk production in pastoral and agro-pastoral production systems of Borana Zone, Oromia Regional State, Southern Ethiopia
}

\author{
Bedane Adane ${ }^{1^{*}}$, Berecha Bayissa ${ }^{1}$, Samuel Tuffa ${ }^{1}$, Tarekegn Tola ${ }^{2}$ and Sileshi Mekon- \\ $n e n^{2}$ \\ ${ }^{1}$ Oromia Agricultural Research Institute, Yabello Pastoral and Dry land Agriculture Research \\ Center, P.O. Box 85, Yabello, Ethiopia \\ ${ }^{2}$ Food and Agriculture Organization of the United Nations, Ethiopia
}

*Corresponding author: bedaneadane@gmail.com

\begin{abstract}
Participatory impact assessment of ticks on Borana cattle milk production was conducted from January 2010 to July 2010. The objectives of this study were to assess the status of tick infestation in relation to climate change, teats blinding and milk production and to estimate the economic losses caused as a result of the effect of ticks on dairy cattle and its implications on food security in Yabello, Moyale and Meo districts of Borana zone. Multi-stage sampling technique was employed and the data was analyzed using descriptive statistics and matrix triangulation. Thus, about six villages "Ollas" were systematically identified and a total of 86 households were interviewed employing questionnaires comprising 6-12 pastoralists and agropastoralists per ten PAs which in sum contained 60-120 individuals who provided information pertaining to the objectives set; in which increase of ticks population at an alarming rate was perceived having several factors affecting and its real impact of blinding on teats which signal loss of milk production which in fact revealed economic loss and implicated food insecurity on vulnerable social groups, specifically children and elders $>80$ years old within the settings. Tick resistance to currently available acaricides was complained by communities. It was observed that acaricides were sold in open market and there was no strong control on illegal veterinary drug vendors. Communities also purchase these acaricides and misuse them which, contributed to the increase of acaricide resistance. This is a good indication for policy makers and local authorities to take strict action on illegal drug vendors.
\end{abstract}

Keywords: Borana zone, Climate change, Impact assessment, Milk production, Participatory epidemiology

http://dx.doi.org/10.4314/evj.v16i1.1 


\section{Introduction}

Ticks and the diseases they transmit are widely distributed throughout the world, particularly in tropical and subtropical regions. It has been estimated that 80 percent of the world's cattle population is exposed to tick infestation (FAO, 1984). Although species of ticks and tick borne diseases (TBDs) differ among ecological regions, their impact on animal production is important wherever they occur. Ticks are widespread in Ethiopia (Pegram, 1981). Fortyfour tick species in 9 genera were recorded in different agro-ecological zones of the country and out of these, 8 tick species belonged to the genus Amblyomma, 2 to Aponomma, 2 to Boophilus, 4 to Haemaphysalis, 9 to Hyalomma, 1 to Ixodes, 15 to Rhipicephalus, 1 to Argas and 2 to Ornithodorous. (Sileshi Mekonnen, et al., 2007). Ticks, apart from transmitting protozoal, rickettsial and viral diseases; they also downgrade hides and skins, reduce meat, milk and wool production, and increase susceptibility to other diseases (De Castro, 1997). Livestock owners and animal health professionals believe that ticks are the major cause of udder damage, a predisposing factor to mastitis resulting in milk production. However, the overall effects of tick infestations on cattle productivity in pastoral and agro-pastoral communities were not well documented. On the top of this, the pastoral and agro-pastoral communities complained that they are not obtaining expected milk from their cows which resulted in the execution of this impact assessment with the following research questions summarized from their complaints. The research questions which were summarized based on complaints by the communities were as follows:

- What causes blindness of teats in newly calving, medium and old aged cows?

- Is there toxicity effect that they cause in infested cattle?

- Does climate change affect the complained problems ticks causing?

- What other risk factors contribute to ticks population increment complained to cause the problem?

Therefore, based on the above stated research questions, reflecting the bottom up research gaps, the following objectives were set and addressed, to assess, the status of tick infestation in relation to climate change, the impact of tick infestation on teats blinding and milk production and to estimate the rate and economic losses caused as a result of ticks infestation on dairy cattle and its implications on food security. 


\section{Materials and methods}

\section{Study area}

The survey was undertaken in pastoral and agro-pastoral production systems which is representative lowland districts of Borana Zone of Oromia Regional State, southern Ethiopia; which is located at 570-775 Kms South of Addis Ababa, bordering northern Kenya and the Somali Regional State of Ethiopia with GPS references ranging (Yabello district PA's (Bildim rasso, Adegalchat and Danbala saden), Moyale district PA's (Afura, Mudhi-ambo, Arganne and Maddo), and Meo district pastoral associations (PAs) (Tesso, Did-baha and Kara-meo) from $\mathrm{N} 03.68640^{\circ} \mathrm{E} 038.89460^{\circ}$ with altitude of 1189 masl to $\mathrm{N}$ $05.11938^{\circ} \mathrm{E} 038.02523^{\circ}$ with altitude of 1645 masl. The Borana plateau, the portion of the Southern Ethiopia rangelands, comprises an area of about 95,000Km² (Coppock, 1994).

\section{Study animals}

The study animals were Boran cattle of Zebu breed best known for its dual purpose as dairy and beef cattle. Milking cows were selected for this study grazed under natural conditions and adapted to arid and semi-arid environment of the settings.

\section{Sampling design}

Multi-stage sampling technique was employed to select districts, pastoral associations (PAs) "Ardas", villages "Ollas" and pastoralist and agro-pastoralist households (HHs). Three districts were randomly selected from the zone and two to four PAs from each district on random basis. About six villages "Ollas" were systematically identified from each PA and 6-12 pastoralist and agropastoralist HHs were selected from each PA for an interview and focus group discussion (Participatory Epidemiology). Information was collected from the pastoral and agro-pastoral communities in both bottom-up and top-down approaches using Participatory Epidemiology (PE) by identifying items to be scored and listing ticks and problems induced by them and then pair-wise ranking of the named items. While summarizing the results median score of the ten PAs were taken for each parameter explored. Gender balance was given particular attention during participatory approach. And also pre-tested semi-structured questionnaire was administered and about $86 \mathrm{HHs}$ were interviewed. 


\section{Data analysis}

The data was entered to Microsoft Excel 2007 and analyzed with the same program by descriptive statistical method, and matrix triangulation.

\section{Results}

Retrospective studies were carried out on the relationships between tick burden and climate change for about 40 years by interviewing elder pastoralists and agro-pastoralists in Borana zone. It has thus been revealed that climate change has direct effect on rainfall distribution patterns, drought periods, pasture conditions and as a consequence on tick distribution and burden. Thus, the reasons stated by these elders specifically on distribution patterns of ticks in the former five consecutive Borana Abba Gadas' periods depicted below (Figure 1) in the line graph is presented as follows:

\section{Abba Gada Goba Bule (1968-1976)}

There were low tick infestations rate during this gada period as the communities complained; and they witnessed that it is attributable to available grass, good rain and bush burning practice by the abba gada period mentioned. They further said that there was limited bush encroachment mainly attributed to bush burning practice by then. But the limited tick available during this abba gada period reported to induce poison (Hadhaa qbaa) that used to kill animals.

\section{Abba Gada Jilo Aga (1976-1984)}

Bush burning was officially banned during this abba gada period by the then Dergue Regime; otherwise other events pertaining to tick distribution is the same with abba gada Goba Bule's period.

\section{Abba Gada Boru Guyo (1984 to 1992)}

The rainfall was little during this abba gada period that resulted in reduced grass density which created favourable condition for tick infestation to be very high ("Silmii fi Diraandisii ni baayyatee"). The community associated increased tick infestation rate with banned bush burning during preceding gada period which as they believe used to reduce tick infestation while they were practicing earlier. There was "Diima Suga Oola" which means "Diima Suga" drought during this gada period.

Abba Gada Boru Madha and Liban Jaldessa (1992-00 to 2000-08) 
During gada period of these two Abba gada's the density of the grass in the vicinity was reported to be highly reduced, ending up with high infestation rate of ticks.

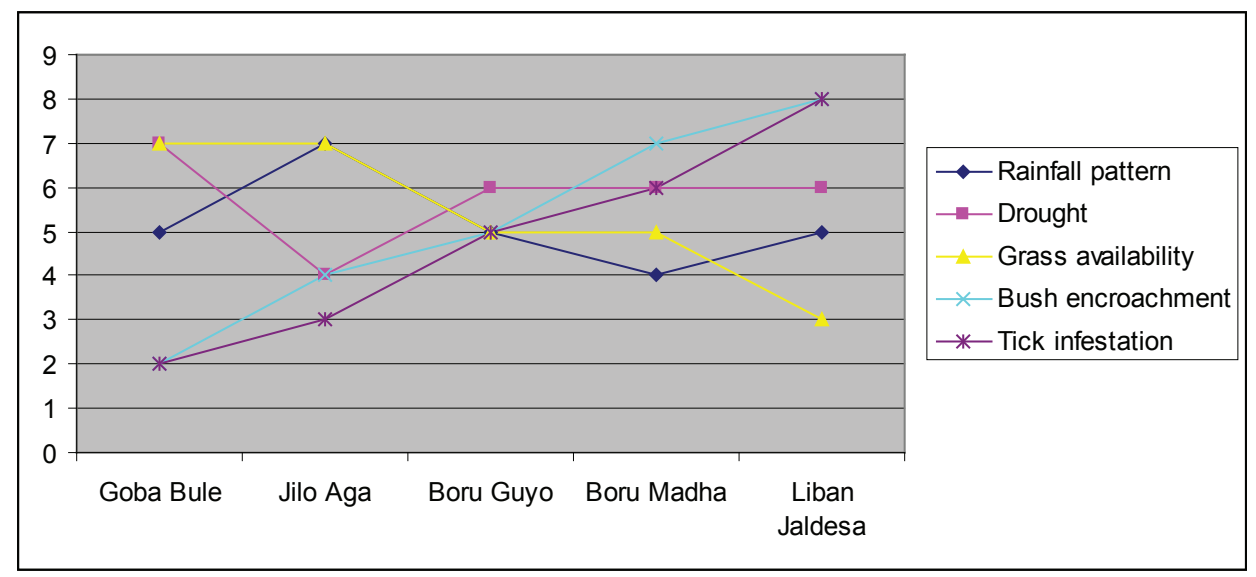

Figure 1: Relationships between tick burden and climate change in five Abba Gada leadership's periods (Each Abba Gada leadership period is eight years)

Conventional meteorological data compiled and depicted below in (Figure 2) is in agreement with the prediction made by the community gathered using participatory epidemiology. Further compliments in agreement to informants' feedback are discussed above in corresponding Abba Gada's. 


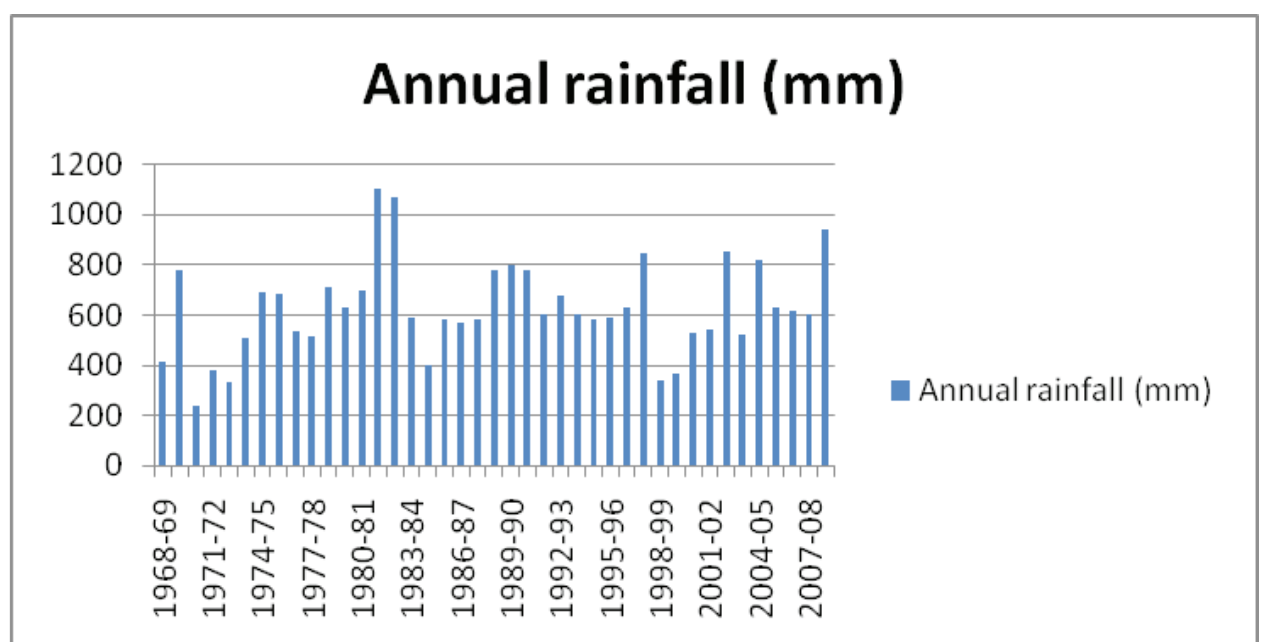

Figure 2: Meteorological data on annual rainfall during period of (1968-2008) of Borana zone

Source: Yabello Pastoral and Dry land Agriculture Research Center Meteorological Station

Magnitude of tick infestation on Udder, Tail, Rear leg, Belly, Fore leg, Dewlap, Neck, Brisket, Head and Ear (Figure 3 \& 4)

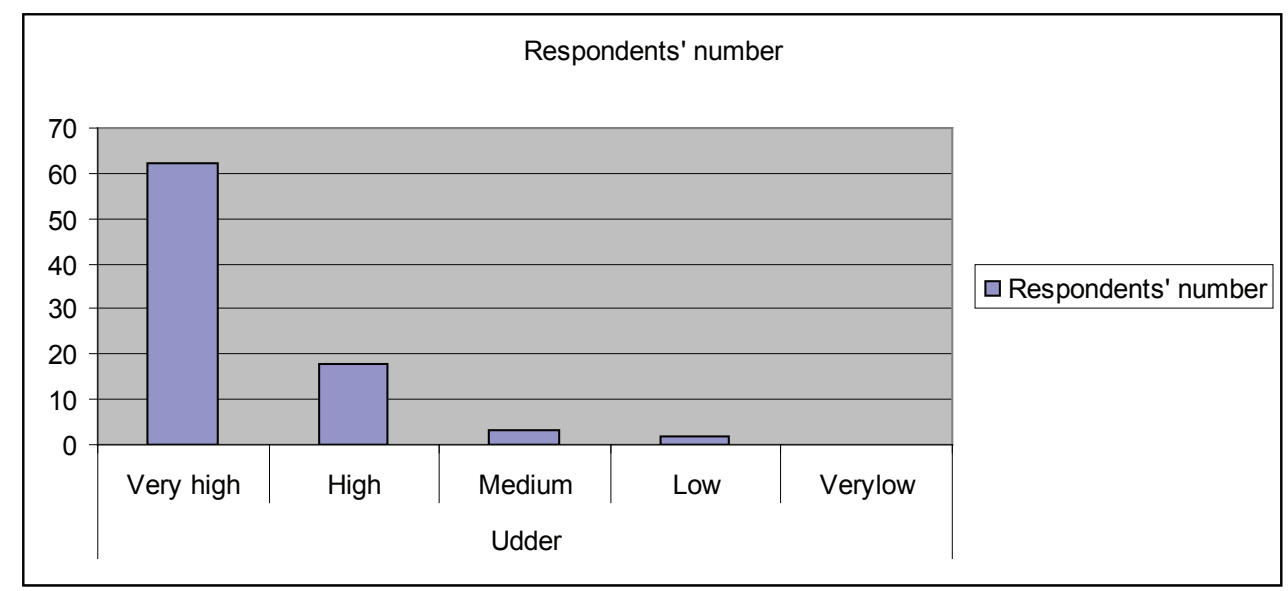

Figure 3: Magnitude of tick infestation on Udder 


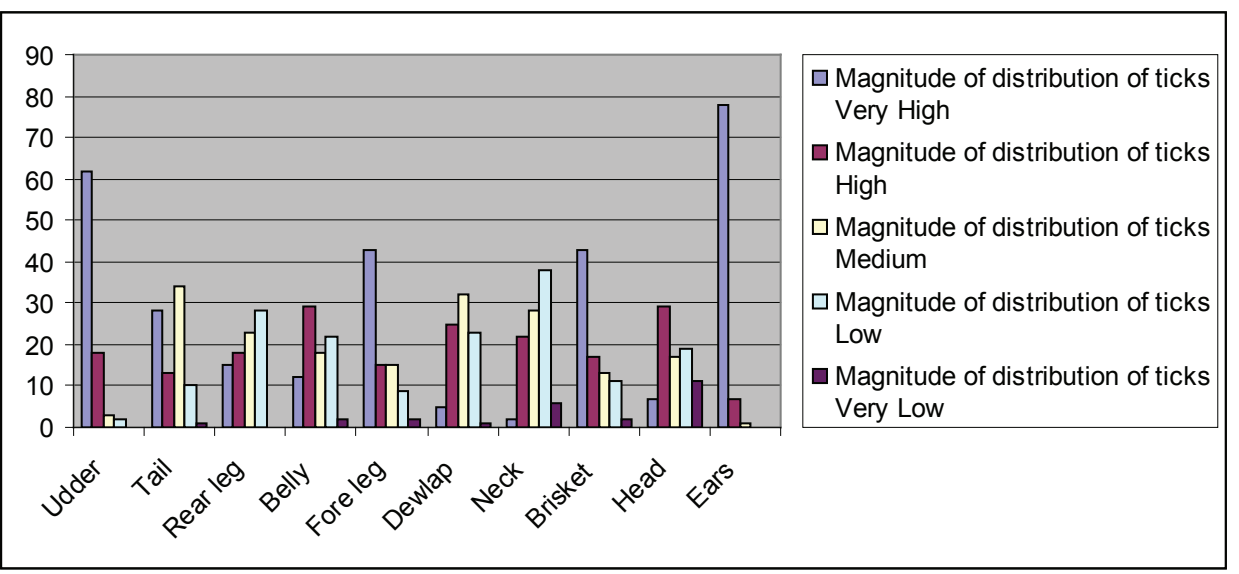

Figure 4: Comparative analysis of ticks' distribution pattern on different body parts of Borana pastoral and agro-pastoral cattle

Milk consumption practice at household level

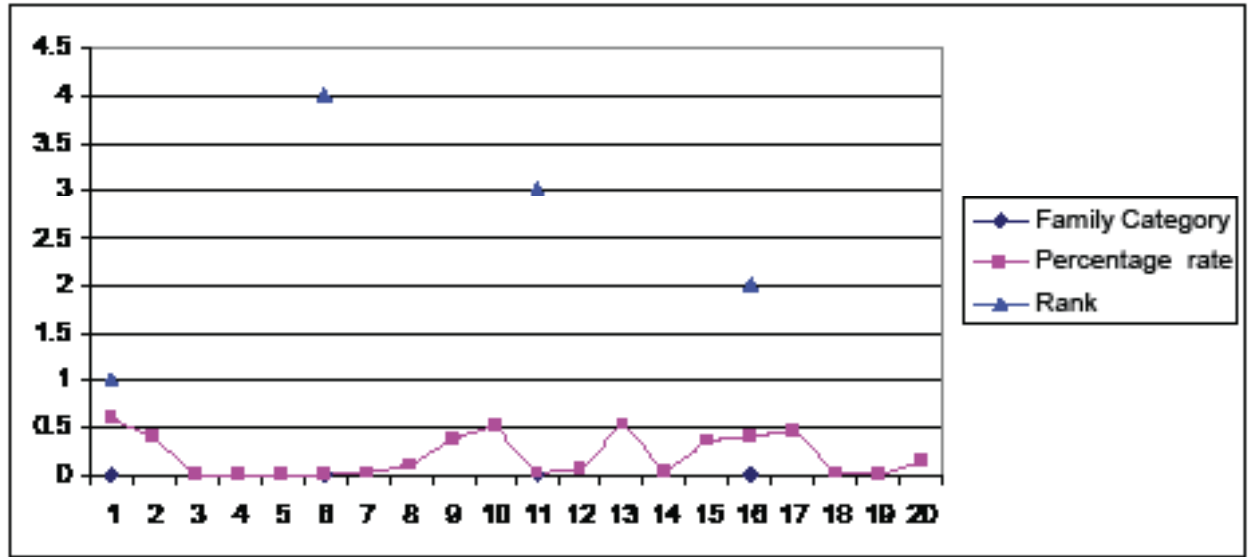

Figure 5: Milk consumption practice at $\mathrm{HH}$ level

Magnitude of teat blinding caused as a result of tick bite 


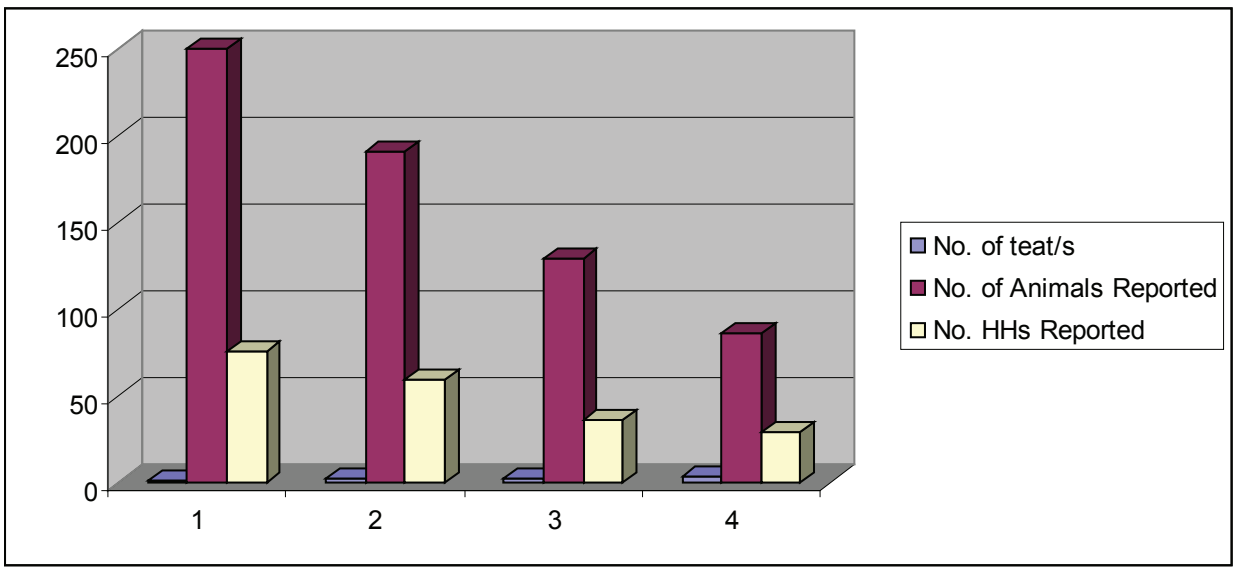

Figure 6: Load of teat blinding

\section{Ticks control measures by pastoral and agro-pastoral communities'}

All of the pastoral and agro-pastoral HHs interviewed agreed on the loss ticks are causing to their animals. The method they utilize to control ticks is washing diazinol with a piece of cloth, spray and hand collection. Meanwhile the percentage rate of $54.65 \%, 7 \%$ and $38.35 \%$ respectively are by washing with a piece of cloth, knap sack spray and both spray and hand collection.

\section{Milk yield reduction}

On cows infested with ticks and blinded teats, the load of blinding on milk production has been reported as $84.88 \%, 11.63 \%$ and $3.49 \%$ as high, medium and low, respectively. With regard to the amount of liter/s of milk explored on recall basis from pastoral and agro-pastoral HHs their cows would give on average milk of 0.74 liter prior to tick infestation and blinding of their teats. Meanwhile the same cows would give 0.43 liter on average after teat blinding. Difference of teat blinding of $70.90 \%$ and $29.70 \%$ with there is difference and no difference among quarters respectively reported. The communities also reported that they discard mastitis milk (Milk down of cows) per day on average for 10.7 days and the lactation length of these mastitic cows is on average 6.94 months; this is 1.42 months less than healthy cows on average. 


\section{Calves mortality rate related to teat blinding}

With regard to calve mortalities, resulting from tick induced teat blinding, $53.49 \%$ reacted that their cows/newly calving heifers calve with blinded teats. Meanwhile $45.35 \%$ do calve with four of their teats intact. In questions raised to $86 \mathrm{HHs} 71.64 \%$ claimed that they faced calves mortality in the past five years and reported 346 calves death from milk shortage, which is huge loss as far as effective reproduction with viability of calves is concerned. Meanwhile, contrary to this, $50 \%$ of questioned individuals provide supplementary feeds to about 241 calves helped survival.

\section{Discussion}

Participatory impact assessment study on the impact of ticks on cattle milk production has revealed that ticks are causing huge loss to cattle milk production and productivity like complained by the pastoral and agro-pastoral communities prior to the execution of this study that resulted from the very complaint need of them witnessing the bottom up approach. As presented above in (Figs $1 \& 2$ ) retrospective studies were carried out on the relationships between ticks burden and climate change for about 40 years (Periods of five consecutive Borana Abba Gada's) by interviewing elder pastoralists and agropastoralists in Borana zone. Climate change has been reported to have direct effect on rainfall distribution patterns, drought periods, pasture conditions and as a consequence on tick distribution and burden like depicted in (Figure 1). And this finding is in agreement with conventional meteorological data compiled and depicted above in (Figure 2) with the prediction made by the community gathered using participatory epidemiology (Figure 1).

In this finding, it has been revealed that, climate change and increasing climate variability affects livestock production systems and the livelihoods of pastoral and agro-pastoral communities who depend on them. According to elders response information was documented on ticks infestations, grass availability, bush encroachment, drought and rainfall distribution patterns in the former five consecutive Borana Abba Gada's periods. Accordingly, there were low tick infestations rate during Abba Gada Goba Bule (1968-1976) gada period as the communities complained; and they witnessed that it is attributable to available grass, good rain and bush burning practice by the abba gada period mentioned. The meteorological data depicted above in (Figure 2) is in agreement with the good rainfall witnessed by informants during this gada period. 
The fall of rain reach the highest peakedness when compared with other gada periods in the stated year's interval (Abba Gada Jilo Aga (1976-1984)) and this is inline with feedback informants provided like indicated in line graph on (Figure 1), which revealed the highest rainfall during this gada period. And also tick infestation increment is in logical agreement with claimed banned bush burning during this gada period. However, the rainfall was low during Abba Gada Boru Guyo (1984 to 1992) gada period that resulted in reduced grass density which created favourable conditions for tick infestations to be very high ("Silmii fi Diraandisii ni baayyatee") this statement is inline with conventional meteorological data evidence depicted above in (Figure 2) as it revealed low rainfall during the gada period in place. The community associated increased tick infestation rate with banned bush burning during preceding gada period which as they believe used to reduce tick infestation while they were practicing earlier. In the same way, during Abba Gada Boru Madha and Liban Jaldessa (1992-00 to 2000-08) gada periods of these two Abba gada's the density of the grass in the vicinity was reported to be highly reduced, ending up with high infestation rate of ticks. This compliment is also in line with conventional meteorological data evidence (Figure 2) above that showed variability in fall pattern of the rainfall during these two gada periods.

In the current participatory tick impact assessment study, it has been revealed that the load of ticks' infestation on udder is very high and inline with communities' complaint of increment of blinding rate of teats (Fig $3 \& 6$ ). The loads of ticks has also been estimated for other predilection sites and as illustrated above in the (Figure 4), the loads of ticks are reported to be very much higher in udder and ears area, followed by brisket area and fore leg; meanwhile the least infested sites are neck and dewlap on Borana cattle of pastoral and agro-pastoral settings as the communities reported. Despite the fact that there was no report on the load in intensity as analysed and depicted above in (Figure 4), there was a report on the predilection sites of ticks (Joseph et al., 1999) which is in consistence with the current assessment finding of distribution of ticks on different body parts of Borana pastoral and agro-pastoral cattle. And also the report on tick species and burden identification reported by (Assefa Regassa, 2001) supplement the current assessment finding.

In this study, analysis of quantitative losses attributed to ticks load in udder has been explored. Accordingly, 656 cows/heifers were reported to have from one to four teats blinded. Of these 656 cows/heifers with teat blinding indicated $38.11 \%, 29.12 \%, 19.67 \%$, and $13.11 \%$ were those with one, two, three and four of their teats blinded respectively. These respective blindness's are as 
reported by 78, 59, 36 and $29 \mathrm{HHs}$ out of 86 pastoral and agro-pastoral $\mathrm{HHs}$ interviewed comprising 55 males and 31 female HHs (Figure 6). The current figure is extremely higher than the finding of $13 \%$ reported by (Coppock, 1994) out of 560 milking cows mean while the current assessment indicated all of 656 consisting of majority of cows and few newly calving heifers. As a result of this, calves mortality rate related to teat blinding has been reported in the recent finding. Based on feedback explored from $86 \mathrm{HHs}$, 71.64\% claimed that they faced calves mortality in the past five years and reported 346 calves death from milk shortage, which is huge loss as far as effective reproduction with viability of calves is concerned.

As depicted above graphically in (Figure 5), in the current findings, milk consumption practice in pastoral and agro-pastoral settings has been studied to reveal food insecurity implications in line with the communities category settings and consumption practice of the milk by them. Thus, milk consumption practice in Borana HHs is at top position by children of age 0-15 years old followed by elders of age > 80 years old "Jaarsa Qulaammoo"; then in 3rd place by elders with age range from 33-80 years and finally adults of age from 15-33 years old. This finding is in agreement with (Sadler and Catley, 2010) rationale in horn of Africa in which they stated that in pastoral communities milk is well known as the staple food of children's diets and therefore is directly linked with the nutritional status of young children.

\section{Conclusion and recommendations}

In this finding, increase of ticks burden at an alarming rate was perceived having several risk factors co-affecting its dynamicity over the 40 years periods of Borana abba gada's and its real impact of blinding on teats which signal loss of milk production which in fact revealed economic loss and implicated food insecurity on vulnerable groups specifically children and elders $>80$ years old and also other groups within the settings. Therefore, based on these conclusive remarks the following recommendations were made:

- Implementation of proper tick control mechanisms giving emphasis to the application of acaricides on udder to reduce the teat blindness.

- Integrated Tick Management (ITM) based on adequate scientific knowledge currently existing to support changes in the philosophy behind tick control in collaboration with other concerned sectors such as Animal Feeds and Range Management and others

- Proper laboratory test of cows for mastitis and udder related problems

Ethiop. Vet. J., 2012, 16 (1), 1-13 
- Awareness creation pertaining to hygienic milking, handling of milk and transmission of mastitis through milking

- As individual perceptions of the need for ticks control by the communities is a bit declined even though affordable, undermining the negative effects ticks are currently causing on their dairy animals and hides should be emphasized by policy-makers and rules and regulations should be enacted accordingly based on local context

- This finding has revealed that the change in climate of the settings has resulted in increased ticks infestation, drought, bush encroachment, and variability of rainfall distribution patterns and reduced grass availability. Thus, these all warrant huge attention by the concerned stakeholders to help adapt the ongoing process in the pastoral and agro-pastoral settings in the current context of the vicinity

- Concerned stakeholders should note and take appropriate intervention measures to bridge food insecurity gap implicated on vulnerable social groups like children and elderly people $>80$ years old during peak tick infestation seasons and drought together with other contributing factors mentioned above in the text.

\section{Acknowledgements}

The authors are grateful to Oromia Agricultural Research Institute (OARI), Yabello Pastoral and Dry land Agriculture Research Center (YPDARC) for the logistics support, UN-FAO for financial support, and technical assistance, the pastoralists and agro-pastoralists of the study districts for devoting their valuable time during execution of the survey/assessment.

\section{References}

Coppock, D.L., 1994. The Borana Plateau of Southern Ethiopia: Synthesis of Pastoral Research, Development, and Changes, 1980-1991. System Study. No. 5. International Livestock Center for Africa, Addis Ababa, Ethiopia, 43-288.

De Castro, J.J., 1997. Sustainable tick and tick-borne disease control in livestock improvement in developing countries. Vet. Parasitol. 71, 77-97.

FAO, 1984. Ticks and tick borne disease control. A practical field manual. Volume I. Tick control. Rome, 299 pp. 
Joseph O., Shawgi M., Hassan and Suliman E., 1999. Taxonomy of African Ticks: An Identification Manual. 124pp.

Pegram, R.G., Hoogstraal, H., and Wassef, H.Y., 1981. Ticks (Acari: Ixodoidea) of Ethiopia. I. Distribution, ecology and host relationship of species infesting livestock. Bull. Ent. Res., 71, 339-359.

Regassa, A., 2001. Tick infestation of Borana cattle in the Borana Province of Ethiopia. Onderstepoort J Vet Res. Mar, 68(1):41-5.

Sadler, K., Catley, A., 2010. Improving the Health and Nutritional Status of Children in Pastoral Communities. Feinstein International Center Tufts University | 200 Boston Avenue, Suite $\quad 4800$ | Medford, Massachusetts 02155 Tel: (617) 627-3423 | Fax: (617) 627-3428 | fic@tufts.edu

Mekonnen, S., Pegram, R.G., Gebre, S., Mekonnen, A., Jobre, Y., and Zewdie, S., 2007. A synthetic review of ixodid (Acari: Ixodidae) and argasid (Acari: Argasidae) ticks in Ethiopia and their possible roles in disease transmission. Ethiopian Veterinary Journal, 11 (2): 1-24. 
